\title{
Obama puts focus on FDA after peanut poisonings
}

\author{
Salmonella outbreak prompts review of US food safety.
}

When the US president worries aloud about the safety of his 7-year-old daughter's peanut butter sandwich, as Barack Obama did last week, it may be safe to assume that change is at last coming to the government's beleaguered food-safety system.

When he announces, in the same interview, "a complete review" of operations at the Food and Drug Administration (FDA), it may be equally reasonable to expect new things at the \$2.3-billion agency responsible for ensuring the safety of most US food and drugs.

Yet no top-to-bottom review will be possible until the agency has a new leader. On 30 January, the White House announced that the appointment of the FDA commissioner was imminent; but that was before the 3 February withdrawal of Tom Daschle, Obama's nominee for secretary of health and human services, to whom the FDA commissioner reports. It is not clear whether Daschle's withdrawal will speed or slow the naming of an FDA chief.

Although roughly two-thirds of the FDA's budget goes to regulating drugs and medical devices, the agency is also responsible for ensuring the safety of $80 \%$ of US foods - and it is in food safety that Obama has run into the FDA's ongoing problems. Since September, 575 people in 43 states - half of them children have fallen ill in an outbreak of Salmonella poisoning that originated at a peanut plant in Georgia.

The outbreak has highlighted the steady weakening of the FDA's food-safety capabili-

"There has to be institutional change." ease outbreaks more than doubled.

Obama himself introduced legislation last year aimed at strengthening and expanding food surveillance technologies. It would also have forced the FDA, the Centers for Disease Control and Prevention in Atlanta, Georgia, and state and local public-health agencies to

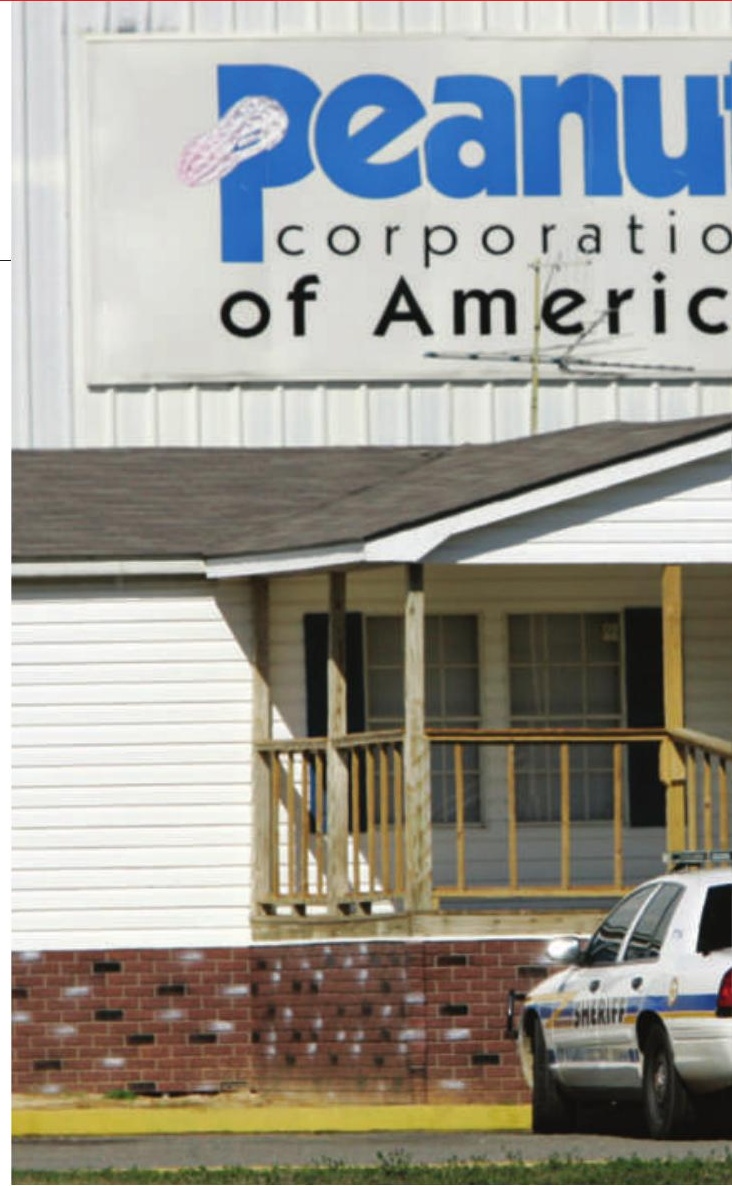

share data on outbreaks of food poisoning and to coordinate investigations more effectively.

At a 5 February hearing of the Senate agri- $\propto$ culture committee, chairman Tom Harkin (Democrat, Iowa) waved a jar of Jif peanut butter, saying: "When Americans can't count on the safety of basic items that go into our children's lunch boxes, then we are in big trouble."

This "is a turning point", says Michael Taylor,

\section{One more step for private Moon mission}

A spectrometer meant to fly to Mars on a European mission in 2016 will get to the Moon first. The Dutch team that is building the instrument last week announced it would send a scaled-up version, dubbed MoonShot, to the lunar surface by 2011 with Odyssey Moon, a company headquartered in the Isle of Man, UK.

If it works, the private MoonOne lander and its successors could serve scientists much as a commercial trucking company serves wholesalers, providing a platform to ferry science instruments and other payloads to the lunar surface.

"The intention is to bring on a new age," says Alan Stern, science mission director for Odyssey Moon and former science chief at NASA. That could mean new opportunities for scientists whose instruments were cut or scaled back in government missions, or whose nations do not have their own lunar spacecraft. "It's an ongoing business that will make sense many years in the future," Stern says.

MoonShot was originally designed to look for organic compounds in the Martian soil using two different types of laser-based spectrometry. The version that will go to Mars on the European Space Agency's ExoMars mission has been cut back to include only a Raman spectrometer, which uses a laser beam to detect chemical signatures, including organic compounds, in surface samples. The version flying privately to the Moon, however, will also have a laser-induced breakdown spectrometer, which will scan the lunar soil and can detect heavy metals. "You shine the laser and just

find out what's there," says Erik Laan, an engineer who helped build the instrument at TNO Science and Industry in Delft, the Netherlands.

MoonShot would be the first Dutch instrument on the lunar surface. A

"It's an ongoing business that will make sense many years in the future." consortium of European companies, including Philips Applied Technologies, Dutch consultants Space Horizon, the Free University in Amsterdam and the Delft University of Technology, will pitch in to pay Odyssey Moon an unspecified amount - although less than US\$10 million - to transport the instrument.

The MoonOne lander is already slated to carry two other commercial payloads. These include a precursor to the International Lunar Observatory, a communications dish 
